\title{
METODOLOGIAS PARA A DETERMINAÇÃO DA GRANULOMETRIA DO SOLO
}

\section{METHODS FOR DETERMINING SOIL PARTICLE SIZE}

\section{Fabio Olivieri Nobile, Hugo Dias Nunes, Vinícius Oliveira Baldocchi}

\author{
Centro Universitário da Fundação Educacional de Barretos. E-mail fonobile @ feb.br, \\ hugooguh_dn@hotmail.com,vinybaldocchi@hotmail.com
}

\begin{abstract}
RESUMO
A erosão é o processo de desagregação e remoção das partículas do solo ou de fragmentos e partículas de rochas, pela ação combinada da gravidade com a água, vento, gelo e organismos. Dentre os principais fatores que exercem influência sobre ela, a declividade é um dos que mais se destacam. As pesquisas realizadas para quantificação granulométrica, ora empregam o peneiramento, ora método do densímetro, ou até mesmo outros métodos, gerando muitas vezes dúvidas sobre a possibilidade de comparação entre estes resultados. A presente pesquisa teve como objeto de estudo a Fazenda Experimental da Prefeitura Municipal de Barretos-SP, onde foram coletados amostras em declividade de 2, 4, 7, 10, 13, 16 e 20\% e com 5 repetições, totalizando 35 amostras. As amostras de solo foram submetidas a análises granulométricas por peneiramento e densimetria e os seus resultados comparados através de análise de variância. Os resultados obtidos apontam que a perda de argila ao longo do declive apresentou comportamento com tendência linear, tendo um aumento em média de $15 \%$ entre o primeiro, e último ponto. Foram constatadas diferenças entre as duas metodologias aplicadas, onde o método do densímetro obteve resultados mais precisos em relação ao do peneiramento. Os resultados indicaram, portanto, que o método da sedimentação tem maior precisão na quantificação das frações de areia, silte e argila, sendo a maior causa de divergência, a maneira como é feito o desagregamento em cada método.
\end{abstract}

Palavras-Chave: Solos. Erosão. Granulometria. Peneiramento. Densimetria.

\begin{abstract}
Erosion is the process of dissolution and removal of soil particles or fragments and rock particles through the action of gravity combined with water, wind, ice and organisms. Among the key factors that exert influence on it, the slope is one of the most distinctive. The research conducted to quantify particle size, now employing the screening, now the hydrometer method, or even other methods, which often generates doubts about the possibility of comparing these results. This research was conducted at the Experimental Farm of the City of Barretos - SP, where samples were collected in slope of 2, 4, 7, 10, 13, 16 and 20\% and 5 repetitions, totaling 35 samples. Soil samples were subjected to particle size analysis by sieving and densitometry and the results compared by analysis of variance. The results indicate that the loss of clay along the slope presented a tendency towards linear, having an increase on average of $15 \%$ between the first and last point. Differences were observed between the two methodologies, where the hydrometer method obtained more accurate results compared to the screening. The results therefore indicate that the sedimentation
\end{abstract}


method has higher accuracy in quantifying the fractions of sand, silt and clay, making it impossible to compare the textural characteristics of the soils obtained by the method of screening, being the major cause of divergence, the way is unbundling made by each method.

Keywords: Soil. Erosion. Granulometry. Sieving. Densimetry.

\section{INTRODUÇÃO}

O termo erosão provém do latim (erodere) e significa "corroer". Nos estudos ligados à ciência da terra, o termo é aplicado aos processos de desgaste da superfície terrestre (solo ou rocha) pela ação da água, do vento, de queimadas, do gelo e de organismos vivos (plantas e animais), além da ação do homem (CAMAPUM DE CARVALHO , 2006).

O solo é a formação natural que se desenvolve na porção superficial da crosta terrestre. Ele é resultado essencialmente da interação dos processos físicos, químicos e biológicos sobre as rochas superficiais da crosta terrestre (DERISIO, 2000).

Com o atual manejo do solo, estima-se em 130 milhões de toneladas perdidas por ano no estado de São Paulo devido à erosão. Essa perda representa $25 \%$ da perda sofrida pelo Brasil inteiro, o que demonstra a grande intensidade da agricultura paulista (BRAGA et al., 2005).

Em grande parte dos casos, a erosão é associada unicamente com a inclinação do terreno. Pelos dados apresentados por Bertoni e Lombardi Neto (2010), pode-se estimar que um terreno com 20 metros de comprimento e $20 \%$ de declividade, tem a mesma perda de solo que um de 180 metros de comprimento e com apenas $1 \%$ de declividade.

Após a retirada da cobertura vegetal, o solo fica exposto a diversas intempéries, como o sol, a chuva, os ventos, culminando na redução de sua permeabilidade, em consequência de sua compactação, desencadeando sérios problemas, como processos erosivos, principalmente do tipo laminar, que além de degradar o solo também o empobrece (GUERRA et al., 2007).

Todo esse processo pode se tornar ainda mais agressivo ao ambiente, pois o solo retirado de um determinado lugar pelo escoamento laminar irá se acumular no leito dos rios, causando assoreamentos, enchentes podendo alterar todo o ecossistema aquático (DERISIO, 2000).

Dentre os principais fatores relacionados com o aumento da degradação ambiental estão as frequentes alterações não planejadas no uso da terra, acima da capacidade de suporte do solo. Nas zonas rurais e urbanas, o manejo inadequado do solo, sem a observância dos limites e riscos de degradação ambiental, tem provocado o desenvolvimento de processos erosivos acelerados, sendo um dos principais fatores causadores da degradação e deterioração da qualidade ambiental (PRUSKI et al., 2006).

O tipo de cultivo do solo pode causar mudanças em sua agregação; uma relação causal com a matéria orgânica do solo (MOS) tem sido evidenciada em diversas pesquisas (AN et al., 2010; ANDERS et al., 2010; FERNÁNDEZ et al., 2010; HUANG et al., 2010).

O conteúdo de MOS é aceito como agente de formação e estabilização dos agregados do solo (SIX et al., 2004; NOELLEMEYER et al., 2008; MULUMBA e LAL, 2008), considerando ainda que o aumento de seu teor deveria ser prioridade não somente para o sequestro de $\mathrm{C}$, mas também para aumento da qualidade, fertilidade, ciclagem de nutrientes e estabilidade da estrutura do solo (LI et al., 2007; BARRETO et al., 2009).

Para acelerar a recuperação de solos fisicamente degradados, Nuernberg et al. (1986) salientaram a importância do cultivo de plantas com crescimento inicial rápido e intenso, que produzam grande quantidade de raízes profundas e de resíduo cultural; a consorciação de duas ou mais espécies culturais e a rotação adequada de culturas também podem contribuir com a restauração da estrutura do solo. Com base no enfoque exposto, objetivou-se avaliar a quantidade de 
areia, silte e argila em área de declive acentuado, através de dois métodos de quantificação, a fim de comprovar a metodologia mais eficaz para análise granulométrica de solo.

\section{MATERIAL E MÉTODOS}

O presente trabalho de pesquisa foi realizado em campo, entre os meses de maio e julho de 2013, localizado na Fazenda Experimental da Prefeitura Municipal de Barretos/SP, compreendida entre as coordenadas $20^{\circ} 33^{\prime}$ de latitude sul, e $48^{\circ} 32^{\prime}$ de longitude oeste. A área utilizada para a retirada do solo foi classificado ao longo de toda a área coletada como Latossolo Vermelho distrófico típico.

O clima da região é classificado como Aw (clima tropical chuvoso com inverno seco) conforme classificação de Koppen com temperaturas médias anuais que variam entre $21{ }^{\circ} \mathrm{C}$ e $27{ }^{\circ} \mathrm{C}$. A precipitação total anual no município tem média entre 1200 a $1400 \mathrm{~mm}$.

Para o levantamento dos dados topográficos, foi utilizado o GPS Oregon 550 da Garmin. Após definido o ponto inicial, todos os demais foram obtidos caminhando-se em linha reta e aguardando a calibração total do GPS. Os dados obtidos através do GPS foram processados utilizando o software GPS Track Maker Pró (GTM).

Foram coletadas amostras em 7 declividades $(2,4,7,10,13,16$ e 20\%) em cada declividade foram coletadas 5 amostras, na camada de $20 \mathrm{~cm}$ de profundidade, e distantes 80 metros de cada ponto (coleta no sentido horizontal), a cada $25 \mathrm{~m}$ percorridos verticalmente se alteravam as declividades onde se coletava mais 5 pontos, totalizando 35 amostras (Figura 1).

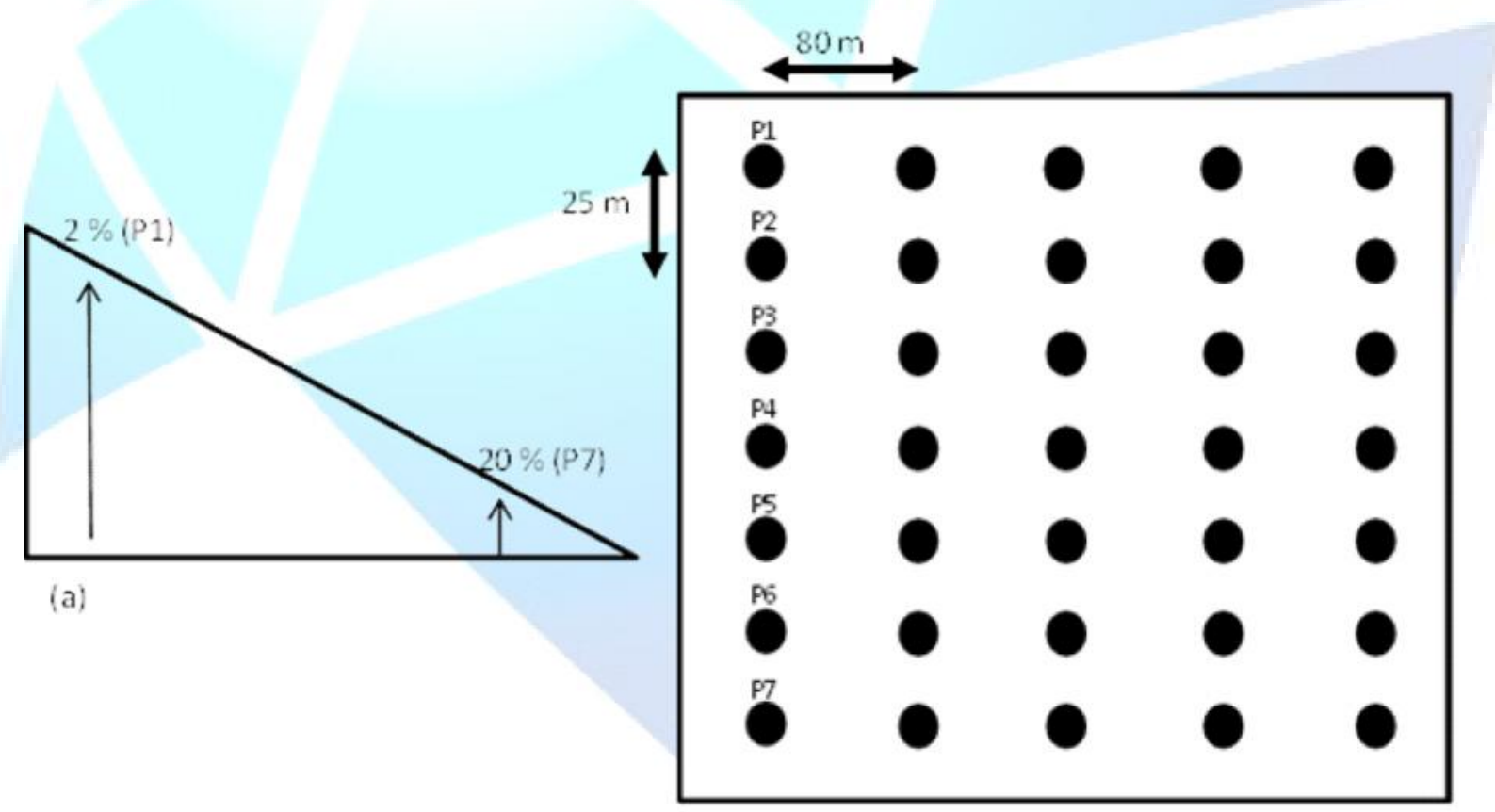

(b)

Figura 1. (a) Perfil topográfico da coleta do solo, (b) croqui do bloco com detalhe da localização dos tratamentos e pontos da coleta do solo

Cada amostra foi coletada o mais próxima possível de cada curva de nível, para que se pudesse observar a perda de solo diante de cada curva. A coleta das amostras para a realização dos ensaios foi realizada segundo a NBR 9603 (ABNT, 1988). 
Inicialmente foi realizada a limpeza do terreno com o auxílio de uma enxada, em seguida foram coletadas com o auxílio de um trado tipo concha, de profundidade de $20 \mathrm{~cm}$ de solo e armazenadas em sacos plásticos lacrados e previamente numerados. A sondagem foi feita a seco, e sem uso de ponteira, visto que o solo se encontrava em boas condições de trabalho.

Após a coleta do material, o mesmo foi levado ao laboratório e colocado na estufa onde permaneceu por 24 horas, com temperatura constante de $110{ }^{\circ} \mathrm{C}$ para que posteriormente fossem feitos os demais ensaios. Os ensaios de classificação do solo foram realizados em conformidade com as Normas Brasileiras pertinentes, a seguir descritas:

- NBR 6459 (ABNT, 1984) - Determinação do limite de liquidez;

- NBR 7180 (ABNT, 1984) - Determinação do limite de plasticidade;

- NBR 7181 (ABNT, 1984) - Análise granulométrica de solos.

As analises granulométricas foram realizadas segundo as normas NBR 6457(ABNT, 1986), NBR 7181(ABNT, 1984) e NBR 7217(ABNT, 1987), e através do método do Densímetro (BOUYOUCOS, 1927, modificado).

O preparo do solo para os ensaios envolveu procedimentos como a secagem em estufa a 110 ${ }^{\circ} \mathrm{C}$, destorroamento e determinação da umidade higroscópica, tais como estabelecidos pela NBR 6457 (ABNT, 1986).

Para o processo de peneiramento foram utilizadas peneiras com abertura de malha de $2 \mathrm{~mm}$, $0,053 \mathrm{~mm}$ e de $0,020 \mathrm{~mm}$ determinando-se a percentagem em peso retida de areia, silte e argila nas $500 \mathrm{~g}$ de solo de cada amostra.

De acordo com DAMIN (2012), as frações constituintes do solo segundo escala granulométrica brasileira da ABNT seguem os valores mostrados na Tabela 1 .

Tabela 1 - Frações constituintes de solo. Fonte: DAMIN (2012)

\begin{tabular}{cc}
\hline Frações de solo & Diâmetro do grão $(\mathbf{m m})$ \\
\hline Pedregulho & 76 a 2,0 \\
Areia & 2,0 a 0,05 \\
Silte & 0,05 a 0,002 \\
Argila & $<0,002$ \\
\hline
\end{tabular}

Segundo Jorge (1985) "as escalas determinando os tamanhos de cada fração, variam com os autores, sendo pessoais e arbitrários nos seus limites para as dimensões de silte e areias". Por meio do peneiramento foi possível observar as porcentagens de areia, silte e argila em cada camada.

O método do densímetro baseia-se no princípio de que a matéria em suspensão (silte e argila) confere determinada densidade ao líquido. Do material passado na peneira de $2 \mathrm{~mm}$, foram tomadas cerca de $120 \mathrm{~g}$ de solo por amostra para a sedimentação. O solo utilizado para a sedimentação foi previamente passado na peneira de $0,053 \mathrm{~mm}$ para que a fração de areia fosse separada, assim permanecendo as frações de silte e argila para a sedimentação do solo fino.

O material foi transferido para um béquer, e adicionado hexametafosfato de sódio para que houvesse a dispersão das partículas, o mesmo foi agitado para que todo o material ficasse imerso, e deixado em repouso por aproximadamente 24 horas. Após o repouso, com o auxílio de uma pisseta todo o material do béquer foi transferido para o copo do aparelho dispersor. Foi adicionada água destilada até que o nível do copo ficasse $5 \mathrm{~cm}$ abaixo das bordas, e submetido a agitação mecânica durante 15 minutos.

Logo em seguida, todo o material restante foi transferido para a proveta graduada, cuidadosamente para que não houvesse perdas e adicionado água destilada até que se atingisse o 
nível de $1.000 \mathrm{~cm}^{3}$. Também foi preparada uma amostra branca com $875 \mathrm{~mL}$ de água destilada e $125 \mathrm{~mL}$ de solução dispersante. Após o material atingir a temperatura ambiente, a proveta foi vedada utilizando uma das mãos, e com o auxílio da outra, foram executados movimentos energéticos de rotação pelos quais a boca da proveta passou de cima pra baixo, e vice versa, pelo período de 1 minuto para que a solução fosse homogeneizada.

Imediatamente depois de terminada a agitação, a proveta foi colocada sobre a mesa, iniciando-se a contagem do tempo com o auxilio de cronômetros. Com a utilização de um densímetro de bulbo simétrico, graduado de 1 a 1,050 foram efetuadas as leituras nas provetas correspondentes ao tempo de sedimentação de $6 \mathrm{~h}$ a contar do início exato da sedimentação para a determinação da fração de argila. A fração de silte foi calculada através da diferença entre a fração areia e argila. A cada leitura do densímetro também foram registradas as temperaturas das amostras dispersas nas provetas.

O densímetro utilizado mede a densidade da suspensão, portanto, foi necessário verificar sua correspondência com o densímetro de Bouyoucos, calibrado em $\mathrm{g}$ de solo/L de suspensão. Os valores de densidade foram transformados em gramas de solo em suspensão de acordo com Camargo et. al., (2009). As leituras também foram corrigidas conforme a temperatura, pois o densímetro de Bouyoucos é calibrado para a temperatura de $68^{\circ} \mathrm{F}$ (CAMARGO et al., 2009).

Para a determinação pelo método do peneiramento pesou-se $500 \mathrm{~g}$ da amostra preparada (terra seca ao ar e passada em peneira de $2 \mathrm{~mm}$ ); colocando-a na parte superior de um jogo de peneiras de 2,0; 0,053 de 0,020 $\mathrm{mm}$ de malha; ligando o agitador por 15 minutos (agitador tipo ROTAP de velocidade controlada e movimentos rotatórios com vibração); retirando-se o conjunto e pesando o solo retido em cada, para utilização do peso no cálculo da porcentagem de agregados; calculando a porcentagem dos agregados retidos em cada peneira.

\section{RESULTADOS E DISCUSSÃO}

Os índices de Limite de Liquidez (LL) e Limite de Plasticidade (LP), referentes ao solo coletado na profundidade de $0-20 \mathrm{~cm}$ foram realizados segundo as normas NBR 6459 (ABNT, 1984) e NBR 7180 (ABNT, 1984), como pode ser observado na Tabelas 2 e 3.

Na Figura 2 pode-se observar o ponto onde é obtido o Limite de Liquidez, por meio da linha de tendência linear e o ponto onde se encontram o eixo x e y. O Limite de Plasticidade é obtido através da média do teor de umidade das amostras, ignorando as amostras que diferiram $5 \%$ ou mais da média.

Com os dois dados, foi encontrado o Índice de plasticidade de 3\%, concluindo-se então, que se trata de um solo que contém plasticidade. Segundo Caputo (1988), os solos com menos de $7 \%$ de IP são classificados como Fracamente Plásticos. Skempton (1953) observou que o índice de plasticidade é diretamente proporcional a fração de argila, em peso e (\%) mais fina que 0,002 $\mathrm{mm}$ em tamanho, na amostra.

O limite de liquidez foi realizado em quatro pontos ao acaso na área experimental, conforme NBR 6459 (ABNT, 1984) que exige a realização de pelo menos três pontos de ensaio coletados ao acaso, cobrindo o intervalo de 35 a 15 golpes.

O limite de plasticidade foi realizado em cinco pontos escolhidos ao acaso a fim de se obter pelo menos três valores de umidade, sendo que nenhum deles poderia diferir de mais de $5 \%$ dessa média de acordo NBR 7180 (ABNT, 1984). 
Tabela 2 - Limite de Liquidez em amostra de solo coletada ao acaso na área experimental, camada de 0-20 $\mathrm{cm}$ de profundidade.

ENSAIO DE CONSISTENCIA

DATA: $11 / 07 / 13$

Cápsula $\mathrm{n}^{\circ}$

Cápsula com solo úmido $(\mathrm{g})$

Cápsula com solo seco $(\mathrm{g})$

Massa de água $(\mathrm{g})$

Tara da cápsula $(\mathrm{g})$

Massa do solo seco (g)

Teor de umidade $\%$

Número de golpes

\section{LIMITE DE LIQUIDEZ}

409,0

52,8

50,5

2,3

36,9

13,6

16,9

32,0
503,0

44,3

42,3

2,0

31,3

11,0

18,2

28,0
509,0

47,2

44,8

2,4

31,9

12,9

18,6

26,0
510,0

49,0

46,2

2,8

31,5

14,6

19,2

21,0

Tabela 3 - Limite de Plasticidade em amostra de solo coletada ao acaso na área experimental, camada de 0-

\begin{tabular}{lccccc}
\multicolumn{7}{c}{$20 \mathrm{~cm}$ de profundidade. } \\
\hline \multicolumn{7}{c}{ LIMITE DE PLASTICIDADE } \\
\hline Cápsula n ${ }^{\circ}$ & 128,0 & 189,0 & 407,0 & 508,0 & 507,0 \\
Cápsula com solo úmido (g) & 30,9 & 30,7 & 35,5 & 34,8 & 35,8 \\
Cápsula com solo seco (g) & 30,4 & 30,1 & 34,7 & 34,3 & 35,1 \\
Massa de água (g) & 0,5 & 0,6 & 0,8 & 0,5 & 0,7 \\
Tara da cápsula (g) & 26,9 & 26,2 & 29,5 & 31,1 & 30,8 \\
Massa do solo seco (g) & 3,5 & 3,9 & 5,2 & 3,2 & 4,3 \\
Teor de Umidade \% & 14,3 & 15,4 & 15,4 & 15,6 & 16,3 \\
\hline
\end{tabular}

Limite de Plasticidade $=16 \%$

Índice de Plasticidade $=3 \%$

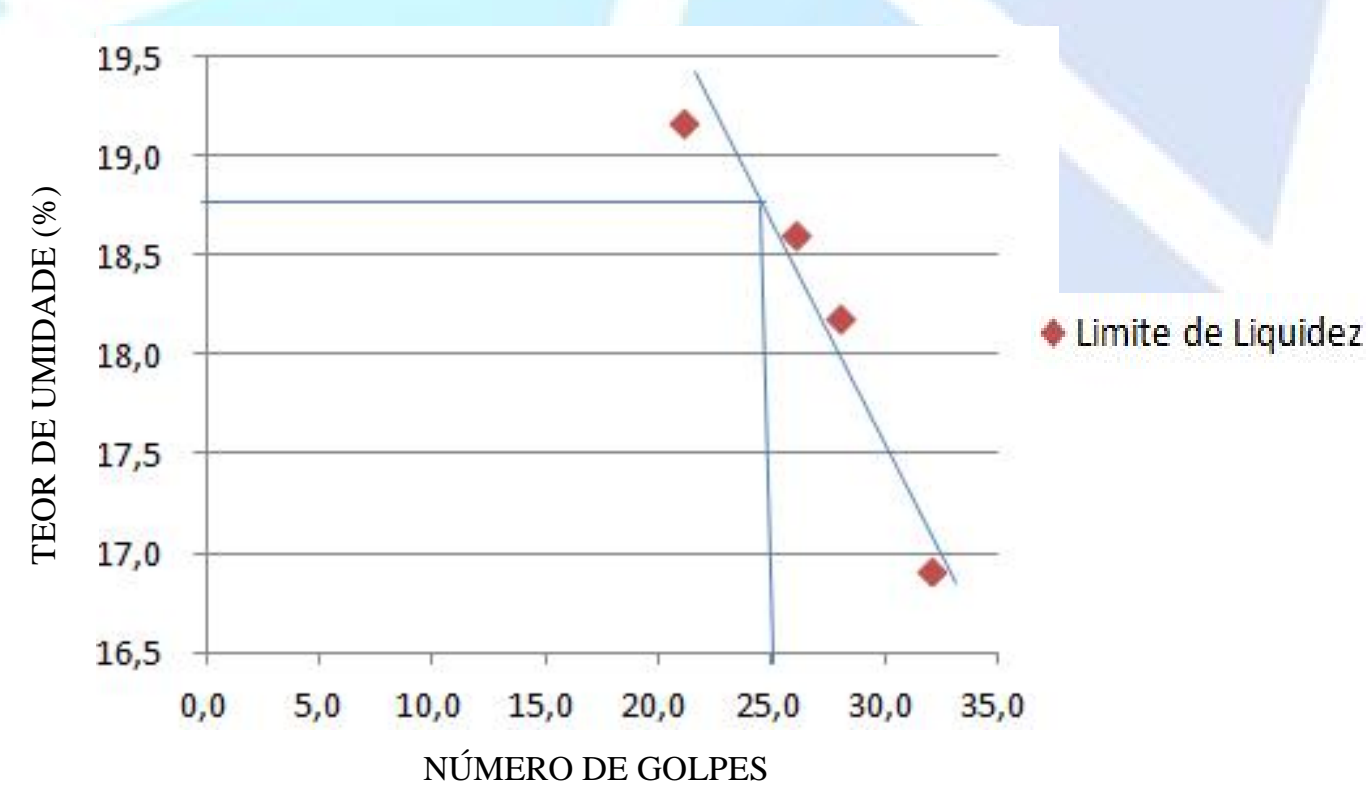

Figura 2. Limite de Liquidez em função do número de golpes. 
Os resultados obtidos pelos métodos do peneiramento e densímetro evidenciaram a perda de areia conforme o aumento do declive. Enquanto o método do peneiramento aponta uma perda de aproximadamente 5\%, o método do densímetro chega a $15 \%$.

$\mathrm{Na}$ fração areia (Figuras 3 e 4), tanto no peneiramento, quanto no método do densímetro ocorreu perda de material ao longo das classes de declividade. No método do peneiramento, ocorreu uma perda de areia de 4,6\% do topo até o ponto mais baixo, enquanto na densímetria esta perda foi de $17,1 \%$. Em relação a esta fração, portanto, as metodologias obtiveram uma diferença de $12,5 \%$ entre uma e outra, porém ambas foram feitas através do peneiramento, o que demonstra que mesmo utilizando a mesma metodologia e o mesmo solo, ocorreram pequenas diferenças no resultado de areia, sendo esta perda diretamente relacionada ao aumento exponencial de argila ao longo do declive.

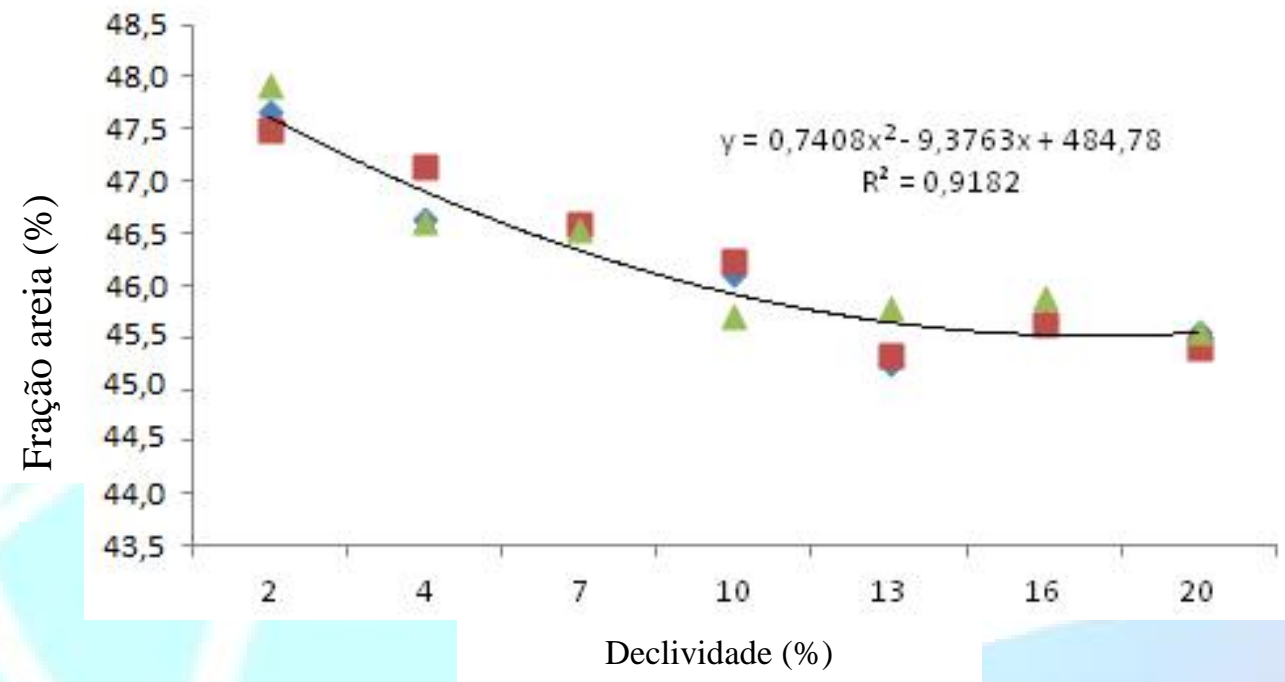

Figura 3. Fração areia $\left(\mathrm{g} \mathrm{kg}^{-1}\right)$ em função da declividade (\%) segundo o método do Peneiramento.

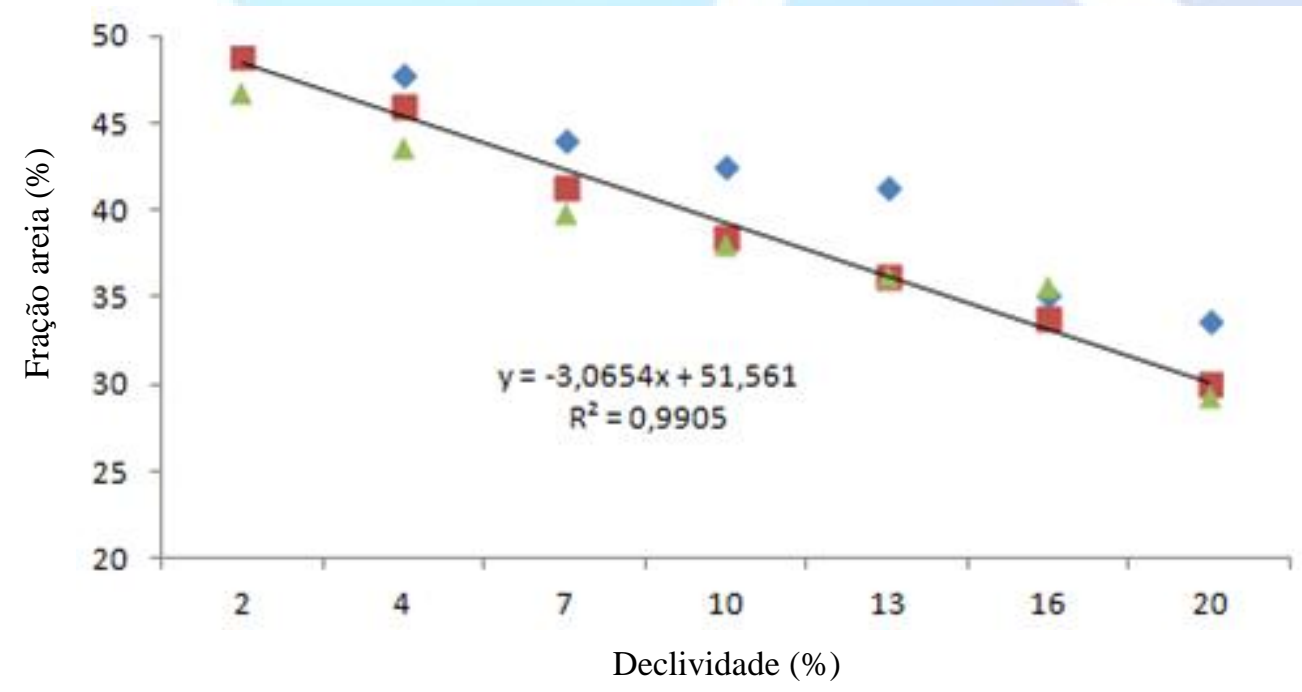

Figura 4. Fração areia (\%) em função da declividade (\%) segundo o método do Densímetro. 
As Figuras 5 e 6 mostram os valores encontrados para o teor de silte, que tiveram divergências de acordo com os métodos, enquanto no peneiramento a quantidade de silte decresceu até a declividade de $16 \%$ e teve um aumento substancial no último ponto, ficando próximo da concentração inicial. $\mathrm{O}$ método do densímetro obteve porcentagens similares para todas as classes de declividade, demostrando uma melhor eficiência para a metodologia empregando a densimetria.

De acordo com VITORINO et al. (2003), parte do silte é composto por agregados de argila formados pela ação de agentes cimentantes.

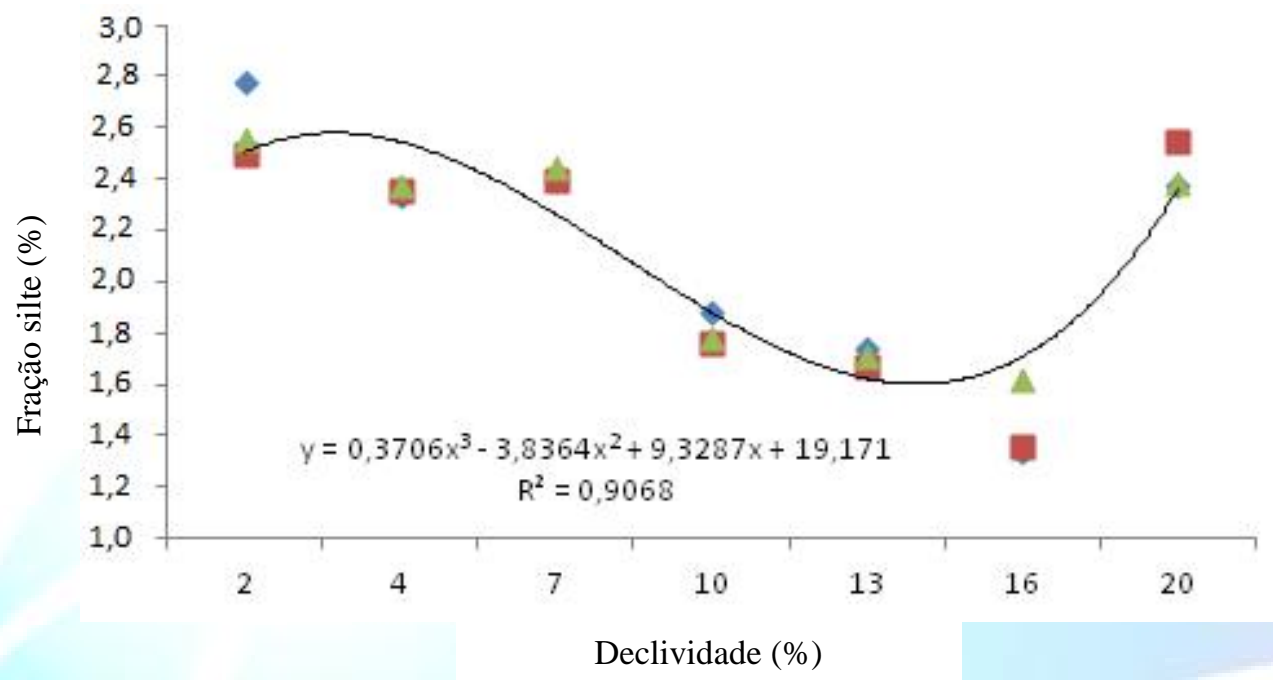

Figura 5. Fração silte $\left(\mathrm{g} \mathrm{kg}^{-1}\right)$ em função da declividade (\%) segundo o método do Peneiramento.

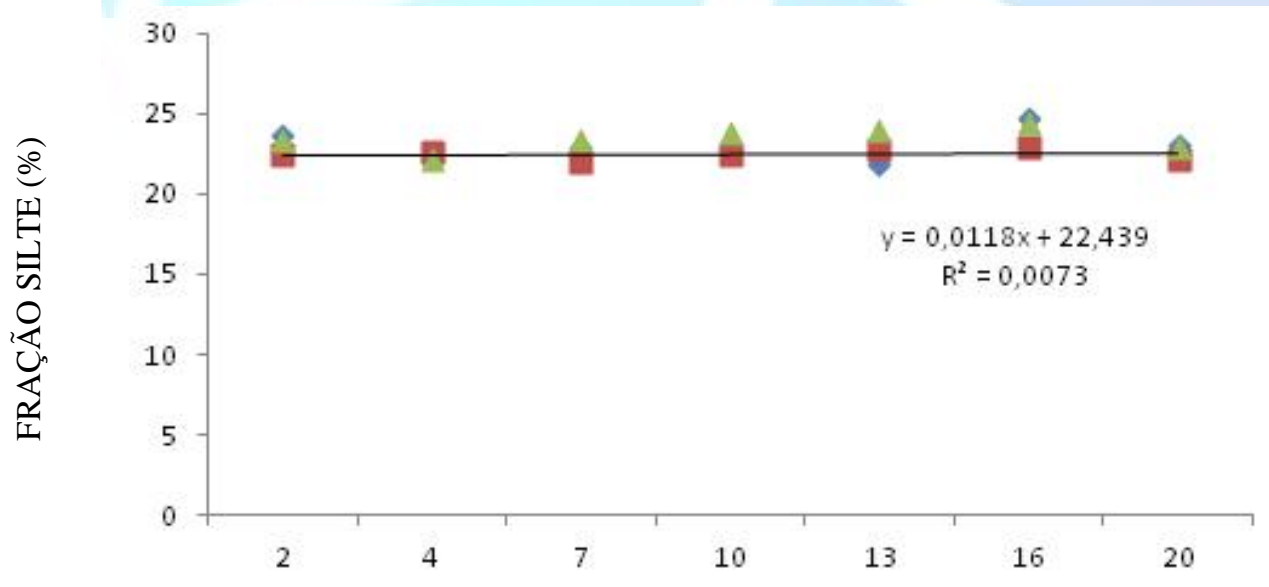

DECLIVIDADE $(\%)$

Figura 6. Fração silte (\%) em função da declividade (\%) segundo o método do Densímetro. 
A maior discrepância apareceu nos teores de silte, na granulometria por peneiramento a porcentagem de silte variou ao longo de todas as classes de declividade. Do primeiro ao penúltimo ponto ocorreu a diminuição da fração silte em média de $72,3 \%$, porém do penúltimo para o último ponto de declive, a fração de silte teve um aumento de $71 \%$, ou seja, praticamente todo o silte não encontrado nas outras classes de declive estava retido no ponto mais baixo do terreno. Devido à baixa plasticidade, de modo geral, o silte é facilmente carregado por fluxos de água, o que explica esta concentração no último ponto.

Devido à alta declividade do terreno, os grãos mais finos tendem a ir para o ponto mais baixo com a ação da erosão. Tanto o silte quanto a argila possuem alta susceptibilidade a erosão hídrica, a argila especificamente, possui esta alta taxa se não possuir solo agregado (BERTONI e LOMBARDI NETO, 2010).

Já no método do densímetro, a porcentagem de silte não obteve variação, permanecendo entre $22 \%$ e $23 \%$, encontrando-se distribuídos próximos à linha de tendência média de distribuição dos dados. Esta diferença nas metodologias pode estar ligada a agregação das partículas de argila nas de silte. Já na densimetria, com o auxílio da defloculação e agitação, essas partículas se desagregam, fazendo com que elas se depositem em uma velocidade proporcional ao seu tamanho.

Na comparação entre as metodologias para a determinação da fração areia (Figuras 7 e 8), verifica-se que apesar das diferenças nos valores quantificados, ambos apresentaram valores crescentes da quantidade de areia com o aumento da declividade do terreno, porém o modo de determinação das frações silte e argila interferiram na exatidão de sua quantificação.

Para a argila total, ambos os métodos apresentaram aumento exponencial, tendo o pico de concentração no último ponto, onde existia a maior declividade, porém pela densimetria, este resultado fica bem mais claro.

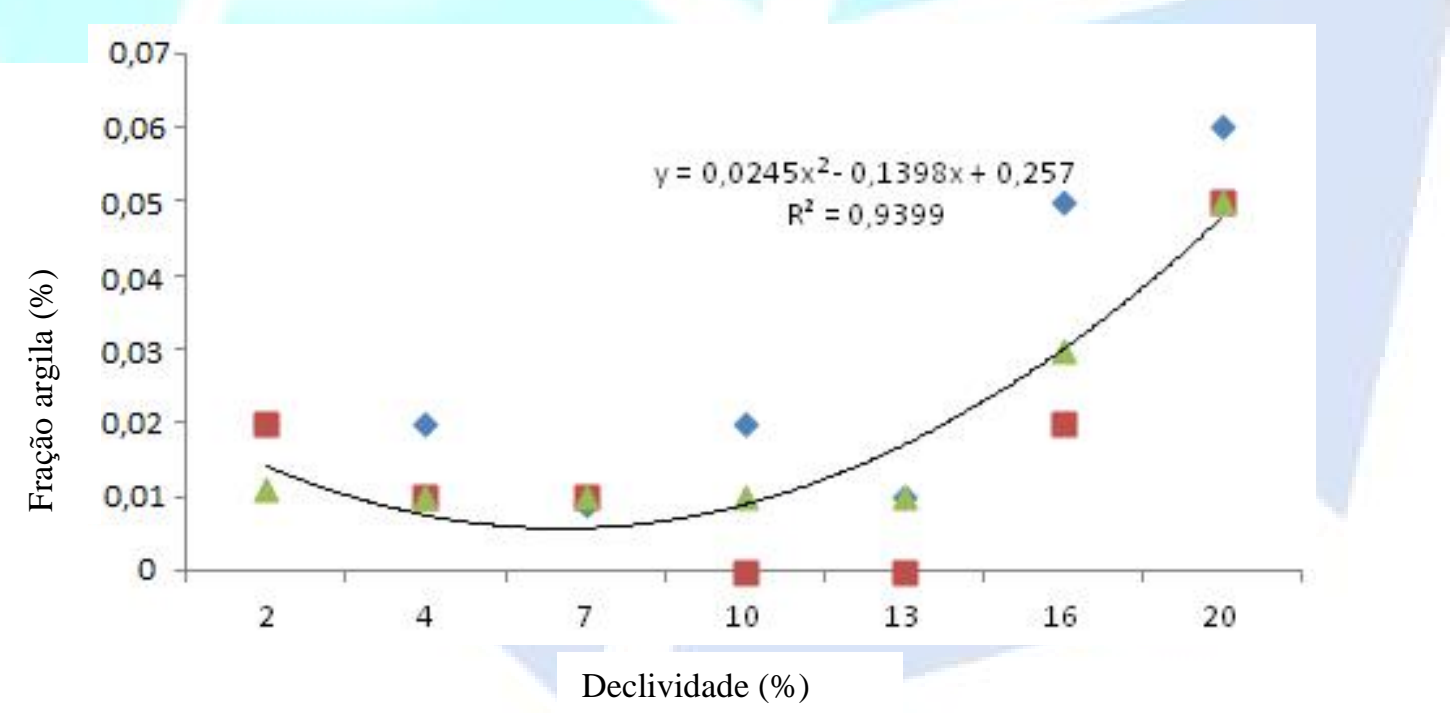

Figura 7. Fração argila $\left(\mathrm{g} \mathrm{kg}^{-1}\right)$ em função da declividade (\%) segundo o método do Peneiramento. 


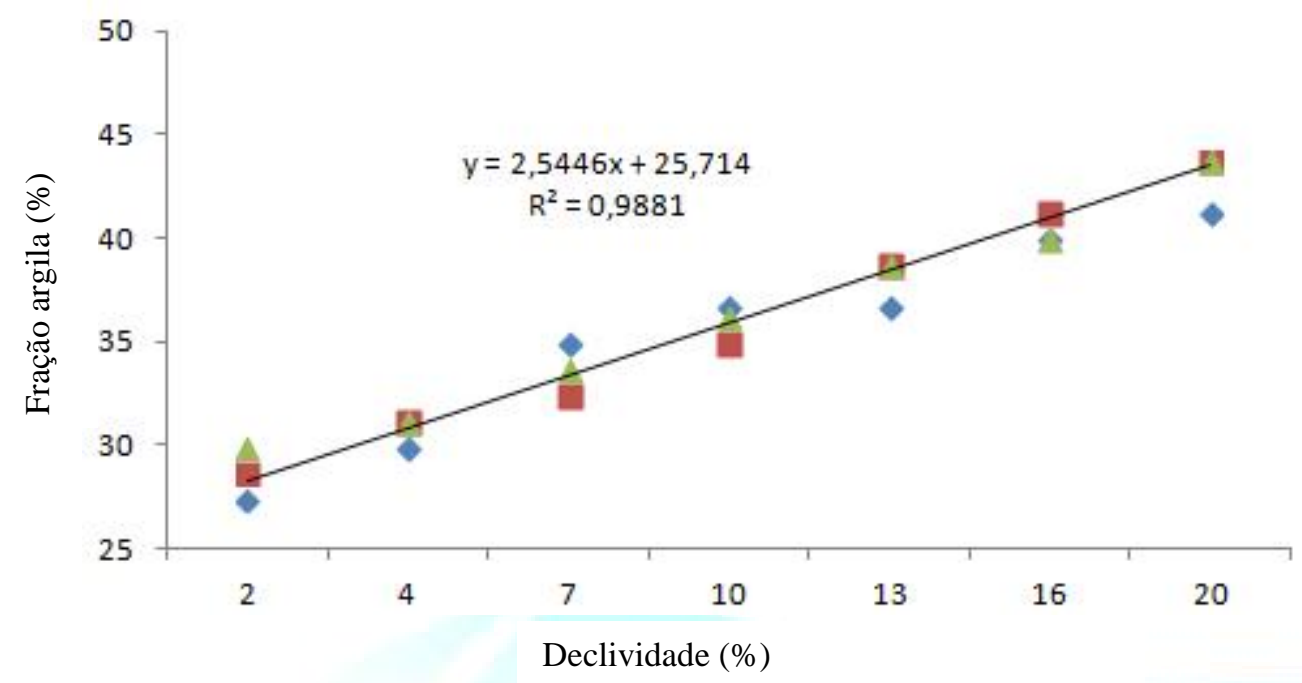

Figura 8. Fração argila (\%) em função da declividade (\%) segundo o método do Densímetro.

Enquanto no peneiramento a fração de argila teve pequenas variações nas classes de 4, 7, $13 \%$, no método do densímetro ela obteve um crescimento exponencial sem quedas nos valores, fortalecendo a conclusão de que a sedimentação dos grãos através do tamanho das partículas é mais eficiente.

Conforme BARRETO (2007), em seu estudo de quantificação da erosão em pastagens com diferentes declives, constatou que de um modo geral, os valores mais altos de perda ocorriam entre as classes de $25-30 \%$, e os mais baixos entre as classes $<9 \%$, mostrando que há aumento das perdas de solo com o aumento da declividade. Estes resultados também foram confirmados por diversos autores (MEYER et al., 1983; WATSON e LAFLEN, 1986; PEREIRA et al., 2003).

Esse comportamento das perdas em relação à declividade pode ser justificado pelo aumento da capacidade erosiva da enxurrada em declives mais acentuados, conforme sugerido por Cogo et al. (2003).

Apesar de os métodos apresentarem certa proximidade no comportamento das curvas em relação à areia e argila, a fração de silte obteve resultados distintos entre os dois métodos. Também ocorreram diferenças entre a porcentagem de cada fração em relação aos dois métodos, esta diferença não influenciou na forma como os grãos foram distribuídos ao longo das amostras, pois ambos os métodos tiveram o pico do teor de argila na maior declividade, porém isto evidencia a maior precisão do método do densímetro em relação ao peneiramento.

O método do peneiramento comparado ao do densímetro possui uma precisão inferior devido a vários fatores. Entre eles, a diferença na quantidade do material empregado em cada metodologia, enquanto no peneiramento são utilizados 500 gramas de solo, no método do densímetro se utiliza 120 gramas. Caso houvessem perdas proporcionais em ambas as metodologias, a do densímetro, por utilizar uma quantidade inferior de material, teria uma perda percentual muito maior, o que poderia acarretar um resultado incorreto da análise.

O fator mais importante está no processo de separação dos grãos. No método da sedimentação, é utilizado o defloculante hexametafosfato de sódio, e após 12 horas de descanso, este solo é colocado no aparelho dispersor e agitado por 15 minutos. Este processo faz com que os grãos que estão agregados venham a se dispersar. No peneiramento, o solo é destorroado e seco, porém estes processos não são suficientes para desagregar totalmente as partículas de solo.

A argila é caracterizada por possuir dimensões microscópicas, ela por si só não apresenta estrutura, mas sim um formato laminar, apresentando uma hierarquia na qual os macroagregados 
(0,25 a $5 \mathrm{~mm}$ de diâmetro) relativamente grandes, são compostos de micro agregados (2 a $250 \mathrm{~m})$ menores, que por sua vez são compostos por agregados ainda menores, até agrupamentos de argila.

A organização hierárquica dos agregados é uma característica da maioria dos solos, com exceção dos solos mais jovens. Pequenas partículas de solo muitas vezes estão oclusas no interior de macro e microagregados. Ao passar o solo por uma peneira, o mesmo pode conter grãos agrupados em outros maiores e não passar pela malha da peneira, isso faz com que os resultados se alterem e a precisão do ensaio diminua.

Conclusão semelhante também obtida por BRAGA et al., (2007), que concluíram que não se deve utilizar quantidade excessiva de solo sobre a peneira, pois assim, muitas partículas finas ficarão inclusas nas grossas, sem a chance de se exporem à abertura de peneira. Entende-se que a amostra deve ser bastante para que cada fração retida seja representativa e sua quantidade suficiente para as análises seguintes. Também concluíram, que o tempo de peneiramento, está diretamente ligado a precisão do ensaio. Para solos com granulometrias mais finas, torna-se essencial à operação com tempos mais longos, para que todas as partículas tenham a chance de se exporem às aberturas de cada peneira.

Logo, o uso correto do método, e uma boa experiência laboratorial tornam-se instrumentos indispensáveis para que a análise por peneiramento possua resultados consistentes.

\section{CONCLUSÕES}

- Os resultados indicaram que o método da sedimentação tem maior precisão na quantificação de da granulometria do solo, em função do desagregamento da partícula; erosivo.

- Quanto maior a declividade maior foi à concentração de argila, evidenciando processo

\section{REFERÊNCIAS}

ABNT - ASSOCIAÇÃO BRASILEIRA DE NORMAS TÉCNICAS. NBR 6459: Solo Determinação do limite de liquidez - método de ensaio. Rio de Janeiro, 6p., 1984.

ABNT - ASSOCIAÇÃO BRASILEIRA DE NORMAS TÉCNICAS. NBR 7180: Solo Determinação do limite de plasticidade - método de ensaio. Rio de Janeiro, 3p., 1984.

ABNT - ASSOCIAÇÃO BRASILEIRA DE NORMAS TÉCNICAS. NBR 7181: Solo - Analise granulométrica - método de ensaio. Rio de Janeiro, 13p., 1984.

ABNT - ASSOCIAÇÃO BRASILEIRA DE NORMAS TÉCNICAS. NBR 6457 - Amostras de solo - Preparação para ensaios de compactação e caracterização. Rio de Janeiro. 6p. 1986.

ABNT - ASSOCIAÇÃO BRASILEIRA DE NORMAS TÉCNICAS. NBR 9603: Solo - Sondagem a trado. Rio de Janeiro, 6p., 1988.

AN, S.; MENTLER, A.; MAYER, H.; BLUM, W.E.H. Soil aggregation, aggregate stability, organic carbon and nitrogen in different soil aggregate fractions under forest and shrub vegetation on the Loess Plateau. China. Catena. Chinatown, v.81:226-233, 2010. 
ANDERS, M.M.; BECK, P.A.; WATKINS, B.K.; GUNTER, S.A.; LUSBY, K.S.; HUBBELL, D.S. Soil aggregates and their associated carbon and nitrogen content in winter annual pastures. Soil Water Manag. Conserv.Oklahoma, v.74:1339-1347, 2010.

BARRETO, A. Quantificação da erosão em pastagem com diferentes declives na microbacia do Ribeirão Salomea. Campina Grande, Bahia, 2007. 56p.

BARRETO, R.C.; MADARI, B.E.; MADDOCK, J.E.L.; MACHADO, P.L.O.A.; TORRES, E.; FRANCHINI, J. \& COSTA, A.R. The impact of soil management on aggregation, carbon stabilization and carbon loss as $\mathrm{CO}_{2}$ in the surface layer of a Rhodic Ferralsol in Southern Brazil Agric. Ecosyst. Environ., v.132:243-251, 2009.

BERTONI, J.; LOMBARDI NETO, F. Conservação do solo. Piracicaba: Ceres, 1985. 392p. São Paulo: Ícone, 2010. 355p.

BOUYOUCOS, G.J. Estimation of the Colloidal Materials in Soils. Science, Philadelphia, v.64: p 362-364. 1927.

BRAGA, A.F.P.; FRANÇA, A.C.S.; SAMPAIO, A.J. Tratamento de minérios: Práticas laboratoriais, Rio de Janeiro, 2007. 570p.

BRAGA, B.;HESPANHOL, I.; CONEJO, L.G.J. Introdução a Engenharia Ambiental. 2. Ed. São Paulo: Editoria Pearson, 2005. 318p.

CAMAPUM de CARVALHO, J.; SALES, M. M.; MOREIRA de SOUSA, N.; SILVA MELO, M.T. Processos Erosivos no Centro Oeste Brasileiro. Editora FINATEC, 2006. 499p.

CAMARGO, O.A. de; MONIZ, A.C.; JORGE, J.A.; VALADARES, J.M.A.S. Métodos de análise química, mineralógica e física de solos do Instituto Agronômico de Campinas. Ed.Rev.Atual. Campinas: Instituto Agronômico, 2009. 77p. (IAC. Boletim técnico, 106).

CAPUTO, H.P. Mecânica dos solos e suas aplicações. $6^{\text {a }}$ ed. Rio de Janeiro: LTC, 1988. 248p.

COGO. N.P.; DENARDIN, J.E.; BERTOL, I.; KOCHHANN, R.A. Retomada, redefinição e intensidade da pesquisa em erosão do solo no Brasil. In: Reunião Brasileira de Manejo e Conservação do Solo e da Água, Manejo Integrado A Ciência do Solo na Produção de Alimentos, 15., Santa Maria, 2004. Anais. Santa Maria, Universidade Federal de Santa Maria, 2004. p.1-26.

DERISIO, J.C. Introdução ao controle de poluição ambiental. Editora Signus, Pelotas, $2^{\circ}$ edição, 2000. 224p.

DAMIN, E. Aplicação do modelo cam-clay modificado ao solo de Cascavel/PR. 2012. 99f. Monografia (Trabalho de Graduação em Engenharia Civil) - Faculdade Assis Gurgacz - FAG, Cascavel, 2012.

FERNÁNDEZ, R.; QUIROGA, A.; ZORATI, C.; NOELLEMEYER, E. Carbon contents and respiration rates of aggregate size fractions under no-till and conventional tillage. Soil Tillage Res., Gangnam-gu, v.109:103-109, 2010.

GUERRA, A.J.T.; SILVA, S.S. BOTELHO, R.G.M. Erosão e conservação dos solos. Editora Bertrand Brasil, São Paulo, $3^{\circ}$ edição, 2007. 340p. 
HUANG, L.; WANG, C.Y.; TAN, W.F.; HU, H.Q.; CAI, C.F.; WANG, M.K. Distribution of organic matter in aggregates of eroded Ultisols, Central China. Soil Tillage Res. Gangnam-gu, v.108:59-67, 2010.

JORGE, J.A. Física e manejo dos solos tropicais. Campinas: Instituto Campineiro de Ensino Agrícola, 1985. 13p.

LI, X.G.; WANG, Z.F.; MA, Q.F.; LI, F.M. Crop cultivation and intensive grazing affect organic C pools and aggregate stability in arid grassland soil. Soil Tillage Res., Gangnam-gu, 95:172-181, 2007.

MEYER, L.D.; ZUHDI, B.A.; COLEMAN, N.L.; PRASAD, S.N. Transport of sand-size sediment along crop row furrows. Transactions of the ASAE, St Joseph, v.26, n.1, p.106-111, 1983.

MULUMBA, L.N.; LAL, R. Mulching effects on select soil properties. Soil Tillage Res., Gangnam-gu, v.98:106-111, 2008.

NOELLEMEYER, E.; FRANK, F.; ALVAREZ, C.; MORAZZO, G.; QUIROGA, A. Carbon contents and aggregation related to soil physical and biological properties under a land-use sequence in the semiarid region of central Argentina. Soil Tillage Res., Gangnam-gu, v.99:179-190, 2008.

NUERNBERG, N.J.; STAMMEL, J.G.; CABEDA, M.S.V. Efeito de sucessão de culturas e tipos de adubação em características físicas de um solo da encosta basáltica sul-rio-grandense. R. Bras. Ci. Solo. Paraná. v.10:185-190, 1986.

PEREIRA, S.B.; PRUSKI, F.F.; SILVA, da D.D.; MATOS, A.T de. Despreendimento e arraste do solo pelo escoamento superficial. Rev. Bras. Engen. Agríc. Amb., Campina Grande, v.7, n.3. p.423-429, 2003.

PRUSKI, F.F.; AMORIM, R.S.S.; SILVA, D.D.; GRIEBELER,N.P.; SILVA, J.M.A. Conservação de solo e água: praticas mecânicas para o controle da erosão hídrica. Viçosa: Universidade Federal de Viçosa, 2006. 240 p.

SIX, J.; BOSSUYT, H.; GRYZE, S.; DENEF, K. A history of research on the link between (micro) aggregates, soil biota, and soil organic matter dynamics. Soil Tillage Res., Gangnam-gu, v.79, p.7$31,2004$.

SKEMPTON, A.W The colloidal activity of clays. III ICSMFE, Zurich, v.1: p. 143-14, 1953.

VITORINO, A.C.T.; FERREIRA, M.M.; CURI, N.; LIMA, J.M.; SILVA, M.L.N.; MOTTA, P.E.F.. Mineralogia, química e estabilidade de agregados do tamanho de silte de solos da Região Sudeste do Brasil. Pesq. Agropec. Bras., Brasília , v.38, n. 1, 2003. 8p.

WATSON, D. A.; LAFLEN, J. M. Soil strength, slope and rainfall intensity effects on interril erosion. Transactions of the ASAE, St Joseph v.29, n.1, p.98-102, 1986. 